\title{
O cuidado à criança em idade escolar: percepções de equipes da Estratégia Saúde da Família
}

\author{
The care for school-aged children: perceptions of \\ Family Health Strategy Care teams \\ El cuidado de los niños en edad escolar: \\ percepciones de los equipos equipos de la \\ Estrategia de Salud de la Familia \\ Marina Lemos Villardi ${ }^{1 *}$, Eliana Goldfarb Cyrino²
}

\section{Palavras-chave: \\ Saúde Escolar \\ Estratégia Saúde da Família \\ Cuidado da Criança \\ Serviços de Saúde da Criança \\ Criança}

\section{Resumo}

Objetivo: Compreender as percepções dos profissionais das equipes de saúde da Estratégia Saúde da Família sobre o cuidado à criança em idade escolar. Métodos: Trata-se de estudo exploratório com abordagem qualitativa. Para coleta de dados, utilizou-se entrevista semiestruturada com 21 profissionais de Unidades de Saúde da Família do município de Botucatu sobre as necessidades de saúde da criança em idade escolar e ações realizadas para elas. Para a organização dos dados gerados nas entrevistas, elegeu-se a análise de conteúdo. Resultados e discussão: Foram identificadas duas categorias de análise que emergiram das falas dos entrevistados: 0 cuidado à criança em idade escolar; Multiprofissionalidade e intersetorialidade: lacunas nas práticas em saúde. Os profissionais de saúde reconhecem a carência de ações em saúde para a criança em idade escolar e explicitam como deve ser esse cuidado, porém a prática revela-se limitada e desarticulada. As atividades multiprofissionais e intersetoriais são destacadas como fundamentais para 0 cuidado à criança em idade escolar, no entanto, são apresentadas como fragmentadas. Considerações Finais: Foi possível identificar que as percepções das demandas da criança em idade escolar não são suficientes para que Equipes de Saúde da Família se mobilizem ou incorporem práticas de cuidado à saúde para elas.

Keywords:

School Health

Family Health Strategy

Child Care

Child Health Services

Child

\section{Abstract}

Objective: The purpose of this study was to understand how Family Health Strategy teams perceive child care at school age. Methods: This is an exploratory study with a qualitative approach. Data collection involved semi-structured interviews with 21 professionals from the Family Health Units in Botucatu, State of São Paulo, Brazil, who were asked about the health needs of children at school age and the actions taken to fulfill them. Content analysis was chosen to organize the data generated in the interviews. Results and discussion: Two categories resulted from the interviews were identified: 1) The care for children at school age, and 2) Multi-professional and inter-sectorial practices: gaps in health practices. Health professionals recognized the shortage of health interventions for children at school age and clearly expressed how they must be cared for, as opposed to how, in practice, these actions were limited and disarticulated. Multi-professional and inter-sectorial practices were considered essential in the care for children at school age; however, they were described as fragmented. Final consideration: It was possible to identify that the perceptions of what is needed for children at school age are insufficient for Family Health Strategy teams to mobilize themselves or incorporate health care practices to those children.

\footnotetext{
${ }^{1}$ Universidade Estadual Paulista (UNESP). mavillardi@yahoo.com.br

2 Universidade Estadual Paulista (UNESP). ecyrino@fmb.unesp.br

${ }^{\star}$ Autor correspondente.

Fonte de financiamento: CAPES.

Conflito de interesses: declaram não haver.

Recebido em:12/03/2012

Aprovado em: 23/10/2012
} 


\section{Palabras clave: Resumen \\ Salud Escolar \\ Estrategia Salud de la Familia \\ Cuidado del Niño \\ Servicios de Salud del Niño \\ Niño \\ Objetivo: Comprender las percepciones de los profesionales de los equipos de salud de la Estrategia de Salud de la Familia sobre el cuidado de los niños en edad escolar. Métodos: Se trata de un estudio exploratorio con enfoque cualitativo. Se entrevistaron 21 profesionales de las Unidades de Salud Familiar del municipio de Botucatu usando entrevistas semi-estructuradas acerca de las necesidades de salud de los niños en edad escolar y de las acciones realizadas frente a tales necesidades. Para organizar los datos generados en las entrevistas, se eligió el análisis de contenido. Resultados y discusión: Se identificaron dos categorías de análisis que surgieron de las declaraciones de los entrevistados: El cuidado de los niños en edad escolar, Multiprofesionalismo e intersectorialidad: deficiencias en las prácticas en salud. Los profesionales de la salud reconocen la falta de acciones en salud para niños en edad escolar y explicitan cómo debe ser ese cuidado, pero la práctica se revela limitada y desarticulada. Las actividades multiprofesionales e intersectoriales son destacadas como fundamentales para el cuidado de los niños en edad escolar, sin embargo, se presentan como fragmentadas. Consideraciones finales Fue posible identificar que percibir las demandas de los niños en edad escolar no es suficientes para que los Equipos de Salud de la Familia se movilicen o incorporen prácticas de cuidado de la salud de los niños.}

\section{Introdução}

A atenção à saúde da criança em idade escolar demanda enfoque intersetorial e multiprofissional que agregue saberes diversificados para uma atenção resolutiva e de qualidade, levando em conta a multiplicidade de fatores que interferem no crescimento, desenvolvimento e integração social da criança ${ }^{1}$.

A complexidade do meio em que as crianças vivem, a presença de velhos e não resolvidos problemas como a tendência à medicalizaçáo do fracasso escolar e a obesidade infantil, ao lado de algumas temáticas de abordagem social, reforçam a necessidade do enfoque intersetorial para a compreensão da situaçáo de saúde da criança em idade escolar em busca de práticas qualificadas, visando à integralidade do cuidado a este grupo ${ }^{2}$.

No caso da atençáo à saúde do escolar, a intersetorialidade se refere à possível articulação de distintos setores, particularmente saúde e educação, para pensar a produção de saúde, no sentido de desenvolver açóes que promovam a saúde da criança ${ }^{1}$.

Neste diálogo intersetorial, é necessária a programação de açôes integradas entre as escolas e as Unidades de Saúde da Família (USF) na medida em que "[...] uma estratégia direcionada para essa população que pretenda ter alcance significativo precisa estar associada à escola, onde grande parte dela se encontra [...]" (p. 534)

Para o Ministério da Saúde:

[...] vista de forma ampliada, a relação entre saúde e educação pode estabelecer a intersecção para a integração dos saberes acumulados por tais campos, uma vez que os processos educativos e os de saúde e doença incluem tanto conscientização e autonomia quanto a necessidade de açôes coletivas e de fomento à participação. (p. 534)
Desta forma, o enfoque multiprofissional é considerado fundamental, pois permite a articulaçáo de distintos saberes a partir da diversidade de experiências profissionais, que, ao se aproximarem, podem engrandecer o cuidado à saúde da criança em idade escolar.

Assim, em busca do cuidado ampliado e efetivo desta criança, a Estratégia Saúde da Família (ESF) tem como objetivo ampliar e qualificar a cobertura na Atenção Primária à Saúde (APS), inclusive como espaço para apreensão das necessidades de saúde ${ }^{4}$ da criança em idade escolar. A ESF permite novos olhares à criança em idade escolar, em tese, pois a considera no contexto de suas relaçóes de vida e história social, física e mental, juntamente com a valorização dos aspectos sociais, econômicos e culturais destas crianças e sua comunidade ${ }^{5,6}$, priorizando açóes de natureza educativa, preventiva ou assistencial, em parceria com as escolas, a fim de produzir práticas positivas sobre a qualidade de vida dos escolares. Tais práticas compreendem, entre outras: a prevenção do uso de drogas, a saúde bucal, a prevenção de violências (física, sexual e bullying ou assédio moral), a prevenção de doenças sexualmente transmissíveis, o aconselhamento contraceptivo, a promoção da saúde, como orientaçôes em relação à nutrição, à prática de atividade física e à cultura da paz ${ }^{7}$.

Entretanto, Cyrino e Pereira ${ }^{1}$ e Miranda et al. ${ }^{8}$ chamam a atenção sobre a falta de preparo das equipes (APS) em responder às necessidades deste grupo, já que são frequentes práticas centradas em soluçóes "biologicistas", medicalizando questôes pedagógicas e/ou sociais, através de encaminhamentos constantes que fortalecem um cuidado segmentado e visão isolada das crianças. Demarzo e Aquilante ${ }^{9}$ defendem que ações restritas ao campo biológico são pouco efetivas em relação à saúde dos escolares, sendo importante a superação de modelos pontuais que buscam responder às demandas emergenciais. Assim, estes autores ${ }^{1,8,9}$ apontam que há necessidade de aumentar a cobertura e melhorar a qualidade dos serviços oferecidos a essa população. 
Segundo Collares e Moysés ${ }^{10}$ :

O termo "medicalização" refere-se ao processo de transformar questôes não médicas eminentemente de origem social e política, em questôes médicas, isto é, tentar encontrar no campo médico as causas e soluçóes para problemas dessa natureza. A "medicalização" ocorre segundo uma concepçáo de ciência médica que discute o processo saúde-doença como centrado no indivíduo, privilegiando a abordagem biológica, organicista. (p. 25) ${ }^{10}$

Em contrapartida, fatores que circundam a vida do escolar como violência urbana, droga, a criança vitimizada, o abuso de todas as formas e a morbimortalidade por acidentes, permitem compreender que a ESF deve traçar diretrizes para o cuidado à saúde da criança em idade escolar, buscando minimizar danos a estas crianças e que se refletem em toda a comunidade ${ }^{8}$.

Percebe-se que há lacunas para a qualificação da atenção à saúde da criança em idade escolar na ESF, justificadas pela tendência à medicalização destas crianças. Trabalhar em todas as dimensóes do cuidado pode ser o caminho na ESF para promover saúde, considerando:

[...] a afetividade, a amorosidade e a capacidade criadora e a busca da felicidade como igualmente relevantes e como indissociáveis das demais dimensóes. Por isso, a promoção da saúde é vivencial e é colada ao sentido de viver e aos saberes acumulados pela ciência e pelas tradições culturais locais e universais. (p. 535)

Assim, o objetivo do presente artigo é compreender as percepçóes de profissionais de equipes de saúde da ESF em relação ao cuidado em saúde oferecido à criança em idade escolar.

Conhecer as dificuldades, fragilidades, conceitos e experiências nas açôes oferecidas à criança em idade escolar pelos profissionais de equipes da ESF torna-se relevantes para refletir em melhorias das práticas de saúde.

\section{Método}

Trata-se de estudo exploratório, pois, segundo Tobar e Yalour ${ }^{11}$, este tipo de estudo é caracterizado por haver escasso ou nenhum conhecimento acumulado e sistematizado sobre o tema. A pesquisa utilizou, como concepçáo metodológica, a abordagem qualitativa, como aquela que:

[...] se aplica ao estudo da história, das relaçôes, das representaçóes, das crenças, das percepçóes e das opiniōes, produtos das interpretaçôes que os humanos fazem a respeito de como vivem, sentem e pensam $[\ldots]$ (p. 57) ${ }^{12}$

Para a coleta de dados adotou-se a entrevista semiestruturada, conjunto de perguntas em ordem específica e relacionadas à experiência ou comportamento, opinióes, valores e conhecimentos, como propóe Minayo ${ }^{12}$. Assim, para desenvolver o trabalho de campo, as entrevistas com os profissionais das Equipes da ESF foram gravadas, com duração média de 40 minutos cada uma.

Para o tratamento dos dados gerados nas entrevistas, utilizou-se a análise de conteúdo, que se define como conjunto de técnicas de análise de comunicação a fim de ter (pela descriçáo do conteúdo das mensagens) indicadores que permitam compreender os conhecimentos relativos à produção das mensagens. A análise de conteúdo busca a interpretação do material qualitativo. Após a leitura das entrevistas, selecionaram-se frases/palavras repetidas com maior frequência, enfatizadas ou singularizadas, sendo que, aquelas que se relacionaram, foram agrupadas, estabelecendo-se categorias e indicando uma expressão que as representasse, para posteriormente efetuar a análise e interpretação dos dados. A análise das categorias neste trabalho foi temática, conforme os temas emergiam do texto ${ }^{13}$.

De modo a alcançar uma postura crítica frente ao conteúdo das falas dos sujeitos entrevistados, o referencial teórico utilizado na discussão dos dados foram autores que discutem: atenção à saúde da criança, ESF e necessidades em saúde, tendo por base a integralidade do cuidado, assim como, açóes intersetoriais e trabalho em equipe.

O estudo foi desenvolvido na cidade de Botucatu, São Paulo, nos anos de 2009 e 2010, e as escolhas da participação das equipes das Unidades de Saúde da Família (USF) pautaram-se de acordo com alguns critérios: disponibilidade da Secretaria Municipal de Saúde de Botucatu; existência de profissionais que lá trabalham há mais de dois anos na USF e que já tinham vínculo com a comunidade; a existência de escola pública de ensino fundamental nas proximidades da USF; e o fato da equipe ter alguma atividade com escolas públicas.

Dentro destes critérios, enquadraram-se na presente amostra duas Unidades de Saúde da Família (USF). A USF(1) pesquisada possui na equipe 5 Agentes Comunitários de Saúde (ACS), 2 Enfermeiros, 2 Dentistas e 2 Médicos. Atendeu, em 2009, 15.068 pessoas. Deste total, 1.358 foram crianças de seis a 14 anos, sendo $9 \%$ dos atendimentos ${ }^{14}$. A comunidade refere, entre seus principais problemas, o consumo de drogas e a gravidez na adolescência ${ }^{15}$. No território da USF(1), há três escolas da rede de ensino público do município, há diversos 
equipamentos sociais e três projetos sociais que atendem crianças em idade escolar.

A USF(2) pesquisada possui, na equipe, 6 Agentes Comunitários de Saúde (ACS), 1 Enfermeiro, 1 Dentista e 2 Médicos. Foram atendidas, em 2009, 7.288 pessoas da área de abrangência desta USF, sendo que, deste total, 681 eram crianças de seis a 14 anos, correspondendo a 9,34\% da populaçáo atendida ${ }^{14}$. No território, há uma escola da rede pública de Ensino Fundamental e se localiza na mesma rua da USF. Trata-se de uma regiáo isolada e distante do centro do município. Entre os principais problemas de saúde da localidade, destacam-se o consumo de drogas e gravidez na adolescência ${ }^{15}$. Trata-se de um bairro carente, de periferia e sem área de lazer para as crianças em idade escolar (ausência de quadras esportivas, praças).

Participaram do estudo 21 profissionais da Estratégia Saúde da Família de Botucatu. Deve-se esclarecer que os 21 sujeitos desta pesquisa totalizavam o universo de profissionais das duas USF (1) e (2), no momento do estudo. Observa-se que quatro auxiliares de enfermagem não foram incluídas, por terem sido recém-contratadas no momento da realização do estudo. Destaca-se que, com a participação destes sujeitos, foi permitida a saturação das informações.

Buscando preservar a identidade dos participantes, estes foram numerados dentro de cada categoria profissional.

O presente artigo é parte do resultado da dissertação de Mestrado em Saúde Pública, aprovada pelo Comitê de Ética em Pesquisa (CEP) da Faculdade de Medicina de BotucatuUnesp (Protocolo 3243-2009) e financiada pela Coordenação de Aperfeiçoamento de Pessoal de Nível Superior do Ministério da Educação (CAPES). A participação no estudo foi voluntária e não houve recusa ou desistência dos entrevistados.

\section{Resultados e discussão}

As unidades pesquisadas foram implantadas na década de 1980, como unidades básicas de saúde e, após 2004, mudaram para USF, com reformulação de suas equipes. A impressão da pesquisadora sobre a USF (1) foi a de uma USF sobrecarregada, com muitos atendimentos eventuais que superam os agendados e com centralidade no trabalho médico. Observou-se grande fluxo de usuários, com elevado número de atendimentos oferecidos à comunidade. $\mathrm{Na}$ época da realização das entrevistas, a USF (2) estava atendendo em um galpão enquanto sua sede encontrava-se em reforma. $\mathrm{O}$ local era escuro, gelado, organizado na medida do possível, e os profissionais e a comunidade estavam adaptados à situação provisória. A pesquisadora presenciou o retorno da Unidade e da Equipe para sua sede, um local bem mais apropriado para o atendimento da população.

Tendo como material empírico as respostas das entrevistas, muito semelhantes nas distintas categorias profissionais pesquisadas das duas USF, foi possível identificar duas categorias temáticas que emergiram das falas dos sujeitos entrevistados: o cuidado à criança em idade escolar e Multiprofissionalidade e intersetorialidade: lacunas nas práticas em saúde.

\section{0 cuidado à criança em idade escolar}

O que se percebe com as falas é a inexistência de açóes em saúde, tendo por base a integralidade do cuidado, oferecida à faixa etária escolar, nas USF. Uma das explicaçóes dadas refere-se à pouca procura dessas crianças às Unidades, vindo apenas quando estão doentes ou querem fazer um exame de sangue.

Criança grande, que a gente fala, vem porque quer fazer um exame de rotina, ver se tá tudo bem (Enfermeira 2).

Eles raramente vêm no posto, não fazem muitos acompanhamentos de rotina. O que mais faz é: se estiver doente vem no posto. (ACS 2)

A baixa frequência da criança em idade escolar nas USF ressalta a consciência dos integrantes das equipes sobre a falta de ações - não levando em conta a presença desta criança, a qual faz parte do seu território de açóes e serviços e de planejamento das intervençóes de saúde oferecidas à comunidade, em decorrência da responsabilizaçáo territorial proposta na atuaçáo das ESF.

Esta procura pela Unidade, restrita para solucionar questôes do campo biológico, pode estar relacionada à forma como a comunidade entende a função da USF. Em estudos sobre a percepção dos usuários sobre a USF ${ }^{16}$, nota-se que a população percebe mudanças no modelo assistencial, entretanto, ainda faz confusão entre o modelo de saúde tradicional e o atual. Trad et al. ${ }^{17}$ referiram também a dificuldade da populaçáo em visualizar a USF ou identificar com precisão sua lógica de funcionamento.

Além da busca por exames e/ou solução para as enfermidades, a procura da criança em idade escolar pela USF ocorre por queixas ligadas ao baixo rendimento na escola (dificuldades de escolarização). A procura pelos profissionais de saúde muitas vezes limita-se em encontrar nos conhecimentos biomédicos soluçôes para as questóes pedagógicas. A forma dos problemas de escolarizaçáo chegarem até a Unidade pode ocorrer através do encaminhamento feito pelas escolas (por parte das professoras) aos profissionais de saúde ou procura 
dos pais pela USF alertados pelos professores a pedirem medicamento visando solucionar o comportamento inadequado do filho na escola.

As professoras encaminham para o posto as crianças com problemas de aprendizagem (Dentista 1).

Crianças que as professoras reclamam falam para os pais virem procurar um médico, pra tomar remédio porque a criança não presta atenção (Médico 1).

Percebe-se que o encaminhamento das crianças aos profissionais de saúde transfere a responsabilidade de "aprender" ao serviço de saúde, depositando a evolução do rendimento do aluno no desempenho do profissional de saúde que trabalha com as chamadas "disfunçôes orgânicas" da criança que não possui bom aproveitamento na escola.

Esta procura por atendimento nas USF corresponde ao que Souza ${ }^{18}$ expóe em estudos sobre medicalização do rendimento escolar, entendido como mau funcionamento fisiológico que acarreta dificuldade de aprendizagem, estimulando o mito de que os conhecedores dessa suposta "disfunção" são os profissionais de saúde; tornando-se uma prática comum entre os profissionais da saúde e da educação.

Ainda sobre intervençôes de cunho biológico, Cruz ${ }^{19}$ revela que o "biopoder" influencia não apenas os corpos, mas a vida, pois produz um saber de controle, científico, em relação ao próprio modo de viver. As intervençóes estritamente biológicas buscam no próprio organismo as causas da doença ou complicação, colocando o social como uma variável imutável, reduzindo as questôes de origem social em causas biológicas ${ }^{19}$.

Buscar meios que provoquem a ruptura com a "medicalizaçáo" contribui para a superaçáo de obstáculos que bloqueiam o desenvolvimento de potencial da criança em idade escolar, de modo a possibilitar açóes significativas voltadas a ela na comunidade em que vive.

\section{Multiprofissionalidade e intersetorialidade: lacunas nas práticas em saúde}

Para os profissionais entrevistados, a escassa realização de atividades intersetoriais é destacada como diálogo desarticulado entre escola e USF, uma vez que os profissionais de saúde admitem não ter apoio dos professores e diretores no desenvolvimento de parcerias.

Eu acho que tem que ter um incentivo da escola, dos professores, diretores incentivarem a fazer parceria de educaçãolsaúde que facilite esse acesso da criança no serviço de saúde (Dentista 2).
Costa et al. ${ }^{20}$ ressaltam que a parceria estabelecida entre escola e USF ocorre, porém, em sua maioria, apenas no plano burocrático, pois a ação intersetorial requer capacidade de negociação e intermediação de conflitos para a resolução ou enfrentamento do problema na possibilidade de agir, que se efetiva nas açóes coletivas e se constrói como um processo ${ }^{21}$.

Embora as falas dos participantes indiquem um diálogo tumultuado nas açoos desenvolvidas entre as USF e a escola, explicam que há algumas açôes em saúde realizadas entre elas.

$\mathrm{Na}$ parte de imunizaçâo tem atividade na escola se eu não $i$, as auxiliares iam para pegar carteirinha, pra fazer a vacina (Enfermeira 2).

Nós examinamos as boquinhas de todas as crianças da escola... Mandamos uma cartinha para aquelas que necessitam de ir no posto de saúde (Dentista 1).

Verifica-se que as práticas de saúde voltadas a este público são pontuais e fragmentadas, não havendo ações permanentes entre os dois setores. Percebe-se que o priorizado são questôes médicas e de saúde bucal, em detrimento da coletividade e do todo.

Quando se trata de práticas que envolvam a integralidade da criança na APS, alguns autores ${ }^{1,9,22}$, assim como este estudo, explicitam que há predomínio da valorização do modelo médico-centrado frente às demandas de saúde pelas quais são acometidas as crianças e se expressam por açóes prioritariamente curativas, centradas na doença e sem a complementaridade das açôes de proteção, promoção e prevenção de agravos à saúde infantil, ou seja, os serviços de saúde interpretam as necessidades da criança em idade escolar como passíveis exclusivamente de prática assistencialista.

Mitre e Gomes ${ }^{23}$ enfatizam que, para as açóes em saúde buscarem caminhos que promovam a integralidade da atenção, faz-se necessário que as demandas sejam interpretadas em suas dimensôes amplas, socioculturais, reconhecendo que as açôes de saúde à criança precisam valorizar suas características como ponto de partida.

Neste contexto, para facilitar as práticas em saúde à criança em idade escolar, os integrantes das USF destacam como fator positivo a presença de mais profissionais de saúde na equipe.

Acho que deveriam ter mais profissionais para ajudar, nas diversas categorias, ligados para acompanhar as crianças, para dar continuidade ao tratamento ou prevenção (Médico 1).

Maior quantidade de profissionais nas equipes facilita a organização e planejamento de práticas em saúde, efetivando a qualidade da atenção à criança em idade escolar. No entanto, percebe-se um "jogo de empurra" sobre os motivos pelos quais a atenção à criança em idade escolar não é trabalhada 
integralmente pelas USF, ou seja, os profissionais não assumem, diretamente, falhas em suas próprias práticas, ao contrário, ressaltam que a dificuldade em realizar açóes em saúde a este público restringe-se, exclusivamente, ao tamanho da equipe e à falta de parceria com as escolas, conforme visto anteriormente.

Estudando também práticas de cuidado à criança nas Unidades Básicas de Saúde (UFS), Ribeiro et al. ${ }^{24}$ revelaram que os profissionais de saúde, ao contrário deste estudo, afirmam claramente que há falta de conhecimento sobre este público, o que dificulta a execução das suas práticas.

Foi apontada, como outro fator que dificulta o trabalho com a integralidade do cuidado da criança, a divergência de opinióes e de prioridades de atenção entre os profissionais da equipe multiprofissional das USF. Esta falta de interação entre os membros das equipes de saúde é exemplificada em uma fala da ACS:

Era uma queixa das professoras relacionada a criar orientação sobre higiene pessoal para as meninas da escola porque elas não têm educação em casa dos pais. Eu até trouxe essa demanda para a Unidade para a enfermeira, porém não fluiu...Não virou nada (ACS3).

Percebe-se que os ACS apresentam mais iniciativa em relaçáo aos demais profissionais, na elaboração de práticas à saúde da criança em idade escolar, pois sua proximidade com a comunidade permite um olhar crítico diante das dificuldades encontradas.

Observa-se que a não existência de "doença" propriamente dita nas crianças não desperta a atenção e mobilização de trabalhos a serem feitos pela UFS, já que não existem complicações de saúde "visíveis" que atinjam os escolares, mas falta de orientaçáo, neste caso, entendido como segundo plano entre as intervençôes da UFS e a maioria dos profissionais de saúde que lá trabalham.

Tal constatação pode ser verificada em outros estudos ${ }^{22}$ em que a baixa interação entre os membros da equipe acarreta práticas fragmentadas que se distanciam do que é preconizado pela integralidade no Sistema Único de Saúde (SUS) na intenção de reconhecer que a prática de saúde é mais do que silenciar um sofrimento aparente.

Samico et al..$^{25}$ pesquisando causas para as dificuldades da presença da criança nas UFS, constatam (assim como esta pesquisa), o predomínio de fatores ligados à organização dos serviços, como ausências de açóes à criança e dificuldades no atendimento ao grupo infantil.

É necessário não simplificar ou reduzir conceitos e práticas sobre a criança em idade escolar, mas partir de suas necessidades e características para questionamentos e elaboração de ações por parte das equipes de saúde. Estruturar e valorizar práticas de saúde voltadas às crianças em idade escolar é essencial na busca de caminhos que qualifiquem a saúde das mesmas.

\section{Considerações finais}

Foi possível identificar que as percepções dos profissionais das Equipes de Saúde da Família às demandas da criança em idade escolar não são suficientes para incorporarem às suas práticas açôes individuais, coletivas ou atividades intersetoriais permanentes com as escolas que identifiquem e atuem em tais demandas. Isto porque, os serviços de saúde priorizam atendimento às evidências biológicas e, por serem menores neste seguimento populacional, não são impulsionadas ações de promoção e de caráter preventivo, além do fato da ESF mobilizar-se diante de grupos populacionais com risco maior de morbimortalidade e vulnerabilidade.

Acredita-se que a atenção à saúde da criança em idade escolar requer a capacitação e/ou atualização dos profissionais das equipes de saúde da família frente às necessidades desta criança, acrescentando à sua prática sensibilidade e conhecimentos sobre o desenvolvimento e crescimento infantil e seus modos de agir sobre si e sobre o meio. Assim, o trabalho multiprofissional desenvolvido nas equipes de saúde precisa ser discutido e organizado, bem como o diálogo com as escolas do território da área de abrangência deve ser valorizado e formulado para viabilizarem redes de práticas e saberes, aperfeiçoando e ampliando as atuaçóes dos profissionais de saúde, tendo em vista a qualidade do cuidado a toda a comunidade.

\section{Referências}

1. Cyrino EG, Pereira MLT. Reflexões sobre uma proposta de integração saúde-escola: o projeto saúde e educação de Botucatu, São Paulo. Cad Saúde Pública. 1999; 15: 39-44. http://dx.doi.org/10.1590/ S0102-311X1999000600005

2. Cyrino EG. Estudo de um programa de saúde escolar em uma escola estadual da periferia de Botucatu. [Dissertação]. São Paulo: Universidade de São Paulo; 1994.

3. Brasil. Ministério da Saúde. Secretaria de Políticas de Saúde. A promoção da saúde no contexto escolar. Rev Saúde Pública. 2002; 36 (4): 533-5. http://dx.doi.org/10.1590/S0034-89102002000400022

4. Brasil. Ministério da Saúde. Saúde da Família: uma estratégia para a reorientação do modelo assistência. [internet]. Brasilia: Ministério da Saúde; 1997 [acesso em 07 jan. 2012]. Disponível em http:// www.4shared.com/office/vYg9EM3M/Sade_da_Famlia_uma_ Estratgia_p.html

5. Brasil. Ministério da Saúde. Secretaria de Atenção à Saúde. Política Nacional de Atenção Básica. 4. ed. Brasília: Ministério da Saúde; 2007. 
6. Ayres JRCM. O cuidado, os modos de ser (do) humano e as práticas de saúde. Saúde Soc. 2004; 13: 16-29. http://dx.doi.org/10.1590/ S0104-12902004000300003

7. Brasil. Ministério da Saúde. Escolas promotoras de saúde: experiências do Brasil. Brasília: Ministério da Saúde; 2006.

8. Miranda MIF, Iossi MA, Ferriani MGC, Cano MAT. Em busca da definição de pautas atuais para o delineamento de estudos sobre a saúde da criança e do adolescente em idade escolar. Rev Latino-Am Enferm. 2000; 8 (6): 83-90. http://dx.doi.org/10.1590/S010411692000000600012

9. Demarzo MMP, Aquilante AG. Saúde escolar e escolas promotoras de saúde. In: Demarzo MMP, Aquilante AG. Programa de atualização em medicina de família e comunidade. Porto Alegre: Artmed: Pan-Americana; 2008. v. 3, p. 9-35.

10. Collares CAL, Moysés MAA. A transformação do espaço pedagógico em espaço clínico: a patologização da educação. In: Alves ML, coordenadores. Cultura e saúde na escola. São Paulo: Fundação para o Desenvolvimento da Educação; 1994. p. 25-31.

11. Tobar F, Yalour MR. Como fazer teses em Saúde Pública. Rio de Janeiro: Editora Fiocruz; 2001.

12. Minayo MCS. O desafio do conhecimento: pesquisa qualitativa em saúde. 5. ed. São Paulo: Hucitec; 1998.

13. Bardin L. Análise de conteúdo. Lisboa: Persona Edições; 1979.

14. Carandina L, Santini MAA, coordenadoras. Botucatu em dados: 2008. Botucatu: FMB- UNESP; 2009.

15. Gonçalves RJ, Soares RA, Troll T. O papel do médico, suas dificuldades, sua vivência e sua relação interdisciplinar no Programa de Saúde da Família de Botucatu. Botucatu: Universidade Estadual Paulista; 2007. Relatório final - $1^{\text {a }}$ etapa Programa PIBIC-CNPQ-UNESP.

16. Neves CF, Cavalcante JPR, Bezerra JIA, Pereira JF, Pitteri JSM, Barbosa MA. Percepções da população sobre o programa saúde da família em Palmas-TO. Rev UFG [serial online]. 2004; 6 Supl Esp [acesso em 2012 jun. 18]. Disponível em http://www.proec.ufg.br/ revista_ufg/familia/D_percepcao.html
17. Trad LAB, Bastos ACS, Santana EM, Nunes MO. Estudo etnográfico da satisfação do usuário do Programa de Saúde da Família (PSF) na Bahia. Ciênc Saúde Coletiva. 2002; 7(Supl 3): 581-9. http://dx.doi. org/10.1590/S1413-81232002000300015

18. Souza WC. Transtorno do déficit de atenção com hiperatividade: um caso clínico ou uma invenção pedagógica. [Tese]. São Paulo: Faculdade de Educação da Universidade de São Paulo; 2009.

19. Cruz MAS. Desafios da clínica contemporânea: novas formas de "manicomialização". In: Angelucci CR, Souza MPR, Morais MLS, Souza BP, Santos FS, Moysés MA, et al., organizadores. Medicalização de crianças e adolescentes: conflitos silenciados pela redução de questões sociais a doença de indivíduos. São Paulo: Casa do Psicólogo; 2010. p. 70-85.

20. Costa GD, Cotta RMM, Reis JR, Ferreira MLSM, Reis RS, Franceschini SCC. Avaliação da atenção à saúde da criança no contexto da Saúde da Família no município de Teixeiras, Minas Gerais (MG, Brasil). Ciênc Saúde Coletiva. 2011; 16: 3229-40. http://dx.doi.org/10.1590/S141381232011000800022

21. Campos GWS. Um método para análise e co-gestão de coletivos. São Paulo: Hucitec; 2000.

22. Sousa FGM, Erdmann AL, Mochel EG. Condições limitadoras para a integralidade do cuidado à criança na atenção básica de saúde. Texto Contexto Enferm. 2011; 20(Supl Esp): 263-71. http://dx.doi. org/10.1590/S0104-07072011000500033

23. Mitre RMA, Gomes R. A promoção do brincar no contexto da hospitalização infantil como ação de saúde. Ciênc Saúde Coletiva. 2004; 9:147-54. http://dx.doi.org/10.1590/S141381232004000100015

24. Ribeiro AM, Silva RRF, Puccini RF. Conhecimentos e práticas de profissionais sobre desenvolvimento da criança na atenção básica à saúde. Rev Paul Pediatr. 2010; 28(Supl 2): 208-14. http://dx.doi. org/10.1590/S0103-05822010000200013

25. Samico I, Hartz ZMA, Felisberto E, Carvalho EF. Atenção à saúde da criança: uma análise do grau de implantação e da satisfação de profissionais e usuários em dois municípios do estado de Pernambuco, Brasil. Rev Bras Saude Mater Infant. 2005; 5(Supl 2): 229-40. http:// dx.doi.org/10.1590/S1519-38292005000200012 